Los sellos postales. Figuritas de la historia argentina Diego Ricardo Ibañez Roka Boletín de Arte (N. ${ }^{\circ}$ 19), e010, septiembre 2019. ISSN 2314-2502

https://doi.org/10.24215/23142502e010

http://papelcosido.fba.unlp.edu.ar/ojs/index.php/boa

Facultad de Bellas Artes. Universidad Nacional de La Plata

La Plata. Buenos Aires. Argentina

\title{
LOS SELLOS POSTALES FIGURITAS DE LA HISTORIA ARGENTINA
}

\section{POSTAGE STAMPS}

\section{FIGURINES OF ARGENTINE HISTORY}

\author{
Diego Ricardo Ibañez Roka \\ irdiegor@gmail.com
}

Facultad de Bellas Artes. Universidad Nacional de La Plata. Argentina

Recibido: 13/2/2019

Aceptado: 9/5/2019

RESUMEN

El presente artículo pretende realizar un análisis desde el Diseño en Comunicación Visual de una selección de estampillas emitidas en la Argentina desde 1856 hasta 2017. Se estudiarán, de manera anacrónica, algunos ejemplares postales, para establecer relaciones entre los elementos formales presentes en las imágenes de estas piezas gráficas y los acontecimientos históricos, políticos, sociales y culturales referenciados en las mismas. Para ello, se tendrán en consideración las distintas miradas historiográficas en cada época. imagen

\section{ABSTRACT}

This article intends to carry out an analysis from the Design in Visual Communication of a selection of stamps issued in Argentina from 1856 to 2017. Some postal copies will be studied in an anachronistic way, trying to establish relations between the formal compositional elements of the images of these pieces graphics, in connection with the historical, political, social and cultural events referenced in them. For this, the different historiographical views present in each era will be taken into consideration.

\section{KEYWORDS}

Stamps; historiography; Argentina; history; image 
Los sellos postales, conocidos popularmente como estampillas, son una serie de piezas gráficas en pequeña escala con motivos impresos en papel engomado. El formato de emisión más utilizado es el rectangular y la función principal de estas es la de comprobante de pago en los envíos postales. Se caracterizan por utilizar imágenes de paisajes, personajes importantes, edificios, entre otros motivos que dan cuenta de sucesos históricos, culturales o científicos de un país.

La historia postal en nuestro territorio comenzó en 1748 con el establecimiento de un correo regular entre Potosí y Buenos Aires. Sin embargo, recién en 1856 fue emitido por la provincia de Corrientes el primer sello postal argentino, ya que aún nuestro país no estaba unificado y cada provincia tenía sus propias estampillas. Buenos Aires y la Confederación Argentina emitían sellos por separado, hasta el año 1880 que se nacionalizaron los servicios postales.

El presente trabajo pretende indagar sobre la historia de nuestro país a partir de una mirada centrada en la comunicación visual. Analizar la forma, el contenido, el tema, el tiempo y el espacio en estas piezas gráficas no solo dará cuenta de las técnicas y las tecnologías de cada época, sino también de la manera de concebir la realidad y de cómo se construyen las imágenes.

\section{LAS ESTAMPILLAS Y LA ORGANIZACIÓN NACIONAL}

El sello postal emitido el 21 de agosto de 1856 por la provincia de Corrientes tenía como imagen el perfil de Ceres, diosa de la agricultura. Buenos Aires emitió ese mismo año una serie conocida popularmente como gouchitos, cuyo valor era expresado en reales, por lo que al adoptar posteriormente el peso como moneda no fue puesta en circulación. El 28 de abril de 1858, Buenos Aires imprimió nuevamente sus sellos postales. Esta vez los puso en circulación y la imagen que contenían era la de un sol y un barco de paletas a vapor. En 1862 aparecieron las estampillas llamadas "escuditos», que contenían el nombre definitivo del país. Hacia 1864 se emitieron una serie de sellos en cuya viñeta se mostraba la efigie del primer presidente argentino, Bernardino Rivadavia [Figura 1].
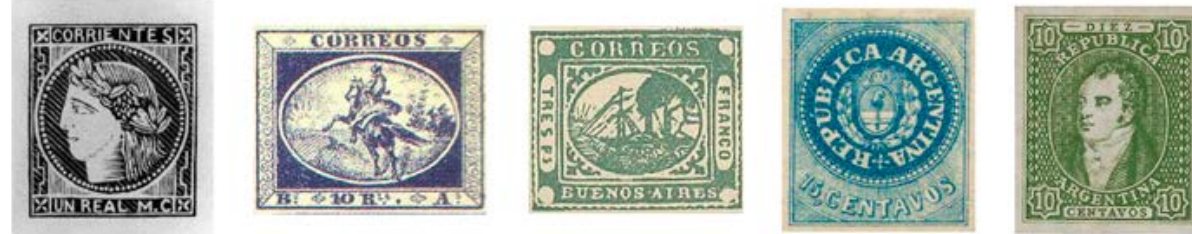

Figura 1. De izquierda a derecha: estampillas de las series: Ceres (Corrientes, 1856); gauchitos (Buenos Aires, 1856), barquitos (Buenos Aires, 1858), escuditos (Argentina, 1862) y Rivadovios (Argentina, 1864)

Estos cinco sellos han sido seleccionados para ejemplificar un período de la Argentina conocido como de Organización Nacional, comprendido entre 1852 y 1880 y que se enmarca en el último tramo de la Crisis del Orden Colonial en América Latina (1780-1880). Los temas plasmados en estas estampillas dan indicios de estos procesos de rupturas y de agrupamientos. Sin embargo, las características formales de las imágenes son muy similares en todas, algo que pareciera mantenerse inalterable hasta pasada la década de 1930.

1 En términos de Daniel Belinche y Mariel Ciafardo (2015), «el espacio construido por el arte no es el espacio real, así como tampoco es su reverso, un espacio irreal. El arte construye universos posibles. A salvo de las leyes de la física, el espacio del arte propone nuevas imágenes (visuales, sonoras, audiovisuales, corporales) del mundo, múltiples concepciones de lo visible, atravesadas por los contextos culturales, por las dimensiones simbólicas, políticas, económicas, religiosas, científicas, ideológicas» (p. 52). 
Por un lado, al observar el catálogo Sellos postoles argentinos 1856-2010 (Mello Teggia, 2009), las estampillas desde 1856 hasta 1930 presentan rasgos formales similares, ya sean dados por el sistema de impresión -la litografía—z o por el comportamiento de la tinta respecto al tipo de papel utilizado. Por otro lado, es destacable la presencia del género retrato ${ }^{3}$ en esta primera etapa histórica. La característica principal de este género es la representación exacto de la apariencia física del retratado. Abundan, entonces, sellos postales de José de San Martín, Bernardino Rivadavia y Manuel Belgrano, por citar algunos ejemplos, imágenes basadas en retratos pictóricos del busto de estos próceres. Pero, ¿Por qué predomina este género? ¿Qué características posee? Natalia Giglietti y Francisco Lemus (2012) señalan:

En este género se combina el aspecto físico, la situación social (personajes importantes como reyes, príncipes, héroes políticos, dignos de ser pintados) y la personalidad (estado espiritual o emotivo, el corócter que distingue al personaje del resto) del retratado (p.12)

La combinación de estos factores justifica el empleo de este género en los sellos postales, porque implica una transferencia de ese estatus intrínseco al retrato y, por sobre todo, propio de los personajes retratados, protagonistas de nuestra historia aún vigentes en diferentes formatos.

Por su parte, utilizar el retrato perfil de la diosa de la agricultura, Ceres, supone un salto poético, ya que en la imagen no se muestran inmensas extensiones de campos sembrados, sino que se utiliza una alegoría y, por metonimia, se hace referencia a la actividad agrícola. Se trata de la principal actividad económica en la implementación de un modelo - el agroexportador- que posicionó a nuestro país entre 1860 y 1930 como el gronero del mundo, un concepto enseñado en las escuelas como algo positivo. No obstante, algunos historiadores como Felipe Pigna, discrepan con esta idea. Al respecto Pigna señala (s. f.):

En realidad se trata de la mejor definición de la condena, decretada por el mercado mundial y aceptada con gusto y beneficio por nuestras oligarquías locales, a ser proveedores de materias primas y compradores de productos elaborados, muchas veces con nuestros mismos productos primarios. Un granero es un depósito, un lugar inanimado. Allí no hay trabajo, valor agregado en términos económicos, sino para unos pocos [...]. Aquí quedaba la riqueza concentrada y la miseria repartida. La Argentino rico lo era para unos pocos, muy pocos (s. p.).

Otro caso interesante es el de la emisión postal de Buenos Aires del año 1856. Recuperar al gaucho manifiesta un cambio en la visión de la sociedad respecto a este personaje, que pasó de ser considerado un vagabundo a ser un referente de la tradición (Ramos, 2014). A diferencia de los retratos de próceres y políticos, a partir de la transformación temática realizada en el Romanticismo, se incorporan personajes que no se caracterizan necesariamente por su rango social elevado (Giglietti \& Lemus, 2012). Sin embargo, la intencionalidad de recuperar a este personaje en la cultura visual tiene la finalidad de otorgarle ese estatus del que carece.

El gaucho como actor social surge durante el período colonial. Un nuevo tipo de población conformada por criollos, es decir, hijos de españoles nacidos en América, y mestizos, hijos de españoles y pueblos originarios. Con un hábito de vida seminómada en el ámbito rural, los gauchos tenían cierta autonomía e independencia económica y social respecto de las autoridades

2 En el catálogo de Daniel Hugo Mello Teggia (2009) dice: «La litografía es un tipo de impresión que se logra mediante el uso de piedras litográficas sobre las que se marca la viñeta a través de una tinta de naturaleza grasa. Al humedecerse con agua, las partes no dibujadas rechazan la tinta de impresión que se adhiere únicamente a la viñeta, luego mediante presión se imprimen las hojas» (p. 532).

3 Los géneros pictóricos responden a una clasificación de la pintura tradicional propuesta por el historiador André Félibien en el año 1667. Su presentación parcial realizada en el prefacio de las conferencias de la Real Academia, señala las distintas categorías artísticas y sus rangos de nobleza y jerarquía donde se enumeran la pintura histórica, la pintura costumbrista, el retrato, el paisaje y, por último, el bodegón 0 naturaleza muerta (Giglietti \& Lemus, 2012). 
coloniales. Estos pobladores vagaban entre las fronteras y subsistían de los intercambios con los pueblos originarios, de los recursos del ambiente y del ganado cimarrón. Las autoridades instauraron un imaginario social despectivo, al señalarlos como vagabundos, forajidos, bandidos, hasta llegar a la denominación de gouchos. La acepción del término y la visión cultural cambió durante las guerras de emancipación, donde los gauchos tuvieron una participación activa como soldados de los ejércitos independentistas, lo que resignificó la palabra al concepto de hombre valiente y servicial (Ramos, 2014).

A diferencia de los casos anteriores, la estampilla que contiene la imagen del barco de paletas a vapor se vincula con el género paisaje. En este caso, la jerarquía del género respecto al resto es menor. Sin embargo, representar un escenario de Buenos Aires como el puerto implica para esta provincia un posicionamiento político. Por aquel entonces, la disputa con la Confederación Argentina por los recursos aduaneros llevó a Buenos Aires a configurarse en un Estado independiente entre los años 1852 y 1861. Morfológicamente el diseño sigue ligado a los sellos postales anteriores y posteriores. Se utiliza la impresión litográfica a una sola tinta negra o a color, sobre soporte de papel blanco, sin dentar, ${ }^{4}$ y con defectos de sobrecarga por la impresión. El tipo de imagen utilizada es la imagen pluma, que se caracteriza por ser de plenos planos.

Luego de las batallas de Cepeda y Pavón, podría decirse que la unificación del territorio se intentó mostrar emitiendo un sello postal donde aparece la denominación actual de nuestro país y otro que recupera a Bernardino Rivadavia como un referente en común. A partir de los Rivadovias, las estampillas presentan mejoras técnicas. Se incorpora la impresión offset, ${ }^{5}$ que permite utilizar imágenes de medios tonos para dar la ilusión de volumen, combinar dos o tres tintas e imprimir sobre papel de mejor calidad, principalmente importado.

En Impresiones porteños. Imagen y palabra en la historio cultural de Buenos Aires (2009), de Laura Malosetti Costa y Marcela Gené, se señala que en el cambio del siglo XIX al XX, se produce en nuestro país un fenómeno similar al ocurrido en Europa, que es la integración de la imagen a la cultura de lo impreso gracias a nuevas tecnologías de reproducción. A la xilografía al hilo y al grabado en cobre se suman el grabado sobre acero, la litografía, la fotografía y el fotograbado. «Cada técnica de reproducción de imágenes difiere de la otra y posee ventajas y límites en sus modos de producción» (Malosetti Costa \& Gené, 2009, p. 112). Parecen ser, a pesar de los cambios políticos, todas muy similares, como si la discontinuidad histórica no encontrara paralelo en la continuidad de la forma, una forma inalterable.

\section{LA IMPORTANCIA DE LA IMAGEN}

La valoración estética de las imágenes de los sellos postales suele ser el motivo que lleva a los filatelistas -es decir, a los coleccionistas de sellos postales - a asignarles un valor más allá del nominal, un valor de colección. Arribar a una definición cerrada del concepto de imagen puede resultar forzado en las artes visuales, por la gran variedad de imágenes que existen actualmente y porque, en palabras de William John Thomas Mitchell (2009): «Aunque tenemos miles de palabras sobre las imágenes, aún no poseemos una teoría satisfactoria sobre ellas [...] la semiótica, las investigaciones filosóficas sobre el arte y la representación convergen en el problema [...] de la cultura visual» (p. 17).

4 «Desde 1856 hasta 1864 los sellos de los Estados Provinciales, los de la Confederación y los primeros de la República Argentina fueron emitidos sin dentar y se los separaba con tijeras. Para facilitar la separación de los sellos, se emitieron estos desde 1864 con planchas perforadas» (Mello Teggia, 2009, p. 531).

5 «Similar a la impresión litográfica pero mediante el uso de chapas metálicas. Estas chapas son colocadas en cilindros rotativos. La impresión se logra al ceder la tinta de la chapa en un cilindro intermedio de caucho y este a su vez imprime sobre papel. Esta impresión se caracteriza por ser muy fina ya que no deja relieve y es sumamente nítida en dibujos y leyenda. A veces a simple vista y otras munido de una lupa podemos observar que el dibujo no es más que una sucesión de diminutos puntos» (Mello Teggia, 2009, p. 532). 
El mundo del arte opera a partir de imágenes ficcionales, es decir, otras realidades construidas por el artista o diseñador, realidades con sus propias normas, recursos, espacio y tiempo. Es por ello que, con relación a los sellos postales, un hecho histórico sucede en un espacio y tiempo determinado, los de la realidad de la vida cotidiana, pero, como afirma Marta Zatonyi (2007), el arte, mediante su capacidad simbólica de construcción de la realidad, crea cultura, genera una serie de desplazamientos simbólicos articulando lo que es con lo que quiere ser.

De este modo, las imágenes plantean una determinada manera de concebir lo real, un modo de pensar, es decir, son ideológicas. La emisión de un sello postal con una determinada imagen es una decisión ideológica. En Cuestiones de estética (1979), Rosa María Ravera define a la ideología de la siguiente manera:

[Una] significación que desborda la perspectiva individual, para convertirse en patrimonio colectivo, como concepción del mundo o cosmovisión pero también como un sistema de evaluaciones, en una síntesis cognitivo-práctica que aúna sistemas de ideas y juicios valorativos [...] un amplio espectro de representaciones mentales tanto a nivel consciente como inconsciente [...] una configuración mental perteneciente a un orden histórico, resultado de un aquí y un ahora adquirido gradualmente a través del tiempo (p. 128).

Esta definición ayuda a comprender la importancia de los sellos postales en los distintos períodos de la conformación de nuestro país, donde cada uno es portador de ideología y da cuenta de valores sociales y culturales de un determinado tiempo.

Recuperar, en la actualidad, este tipo de imágenes para su análisis, sugiere hacerlo enmarcado en el concepto de cultura visual. Nicholas Mirzoeff (2003) sostiene que «la cultura visual aleja nuestra atención de los escenarios de observación estructurados y formales como el cine y los museos, y la centra en la experiencia visual de la vida cotidiana» (p. 25). Al transitar en sobres o en manos de un coleccionista, los sellos postales trascienden el día a día gracias a su originalidad, temática o resolución técnica.

\section{TÉCNICAS Y TECNOLOGÍAS DE IMPRESIÓN}

La imagen impresa múltiple comienza a circular hacia el siglo XV con el desarrollo de la imprenta y de técnicas como el grabado, la calcografía, la litografía y finalmente la fotografía, que permiten su reproducción mecánica y masiva (De Rueda, 2009). Una suerte de democratización de la imagen. Una mirada desde el diseño en comunicación visual, permite apreciar una evolución en los métodos de impresión y de dentado, en los soportes y en los recursos gráficos, que van desde la tradicional filigrana hasta el empleo de tintas especiales o el uso de terminaciones superficiales como lacas, relieves y perfumes. A continuación se desarrollarán una serie de casos que ejemplifican estos recursos mencionados.

Por el 50. aniversario del fallecimiento de Eva Perón, en el año 2002, se emitió una serie de cuatro estampillas entre las cuales se destaca el primer sello postal argentino realizado en sobrerrelieve, evocando la idea del busto de perfil de Evito. Se observa nuevamente, pero en la contemporaneidad, el uso del género retrato en las estampillas, esta vez a través de una cita intertextual con otra disciplina: la escultura. La tecnología actual permite este tipo de reproducción, lo que brinda una pieza de una delicadeza exquisita y alude, también, a los miles de bustos que en el país se han erigido en honor a Eva Perón.

En 2007 se emitió la primera estampilla argentina con efecto visual en tres dimensiones. Es el caso del sello postal del meteorito Choco, considerado el segundo más grande del planeta, que se conserva en esa provincia argentina. La pieza gráfica utiliza el recurso de la fotografía a color y requiere de anteojos adecuados para apreciar la ilusión 3D. 
En 2014, la emisión del sello Recuperación de la Soberonía Aerocomercial presentaba en su diseño una tinta especial que se cargaba con la luz y se iluminaba en la oscuridad de manera fluorescente. En formato de hoja block, la imagen muestra la parte icónica de la marca Aerolíneas Argentinas, el águila sobre un cielo azul, que se repite sutilmente en laca brillante sobre el firmamento. También se observa una ruta de aterrizaje/despegue negra y, a modo de infografía, distintos datos sobre la recuperación de la aerolínea de bandera que se despliegan mediante líneas en tinta plata desde la silueta de un avión.

Por último, otro ejemplo singular es la primera estampilla argentina perfumada. En este caso, en 2017, se emitió una serie de sellos postales con la fotografía en escala de grises de Roberto Sánchez - Sandro - con su nombre en letras doradas, inscripciones en rojo y blanco, y el inconfundible aroma a rosas que lo caracterizaba. ${ }^{6}$

Estos ejemplos destacados presentan saltos temporales más cercanos a la actualidad y, gracias a las nuevas técnicas de manipulación de imágenes, ejemplifican nuevos modos de reproducción. El formato de estos sellos evidencia la importancia del encuadre como una operación de selección en la imagen, ya sea porque el marco implícito determina un sector del campo visual de la fotografía original o bien porque para ser utilizado, el sello postal se desprende de la hoja block, inaugurando un nuevo universo representado [Figura 2].
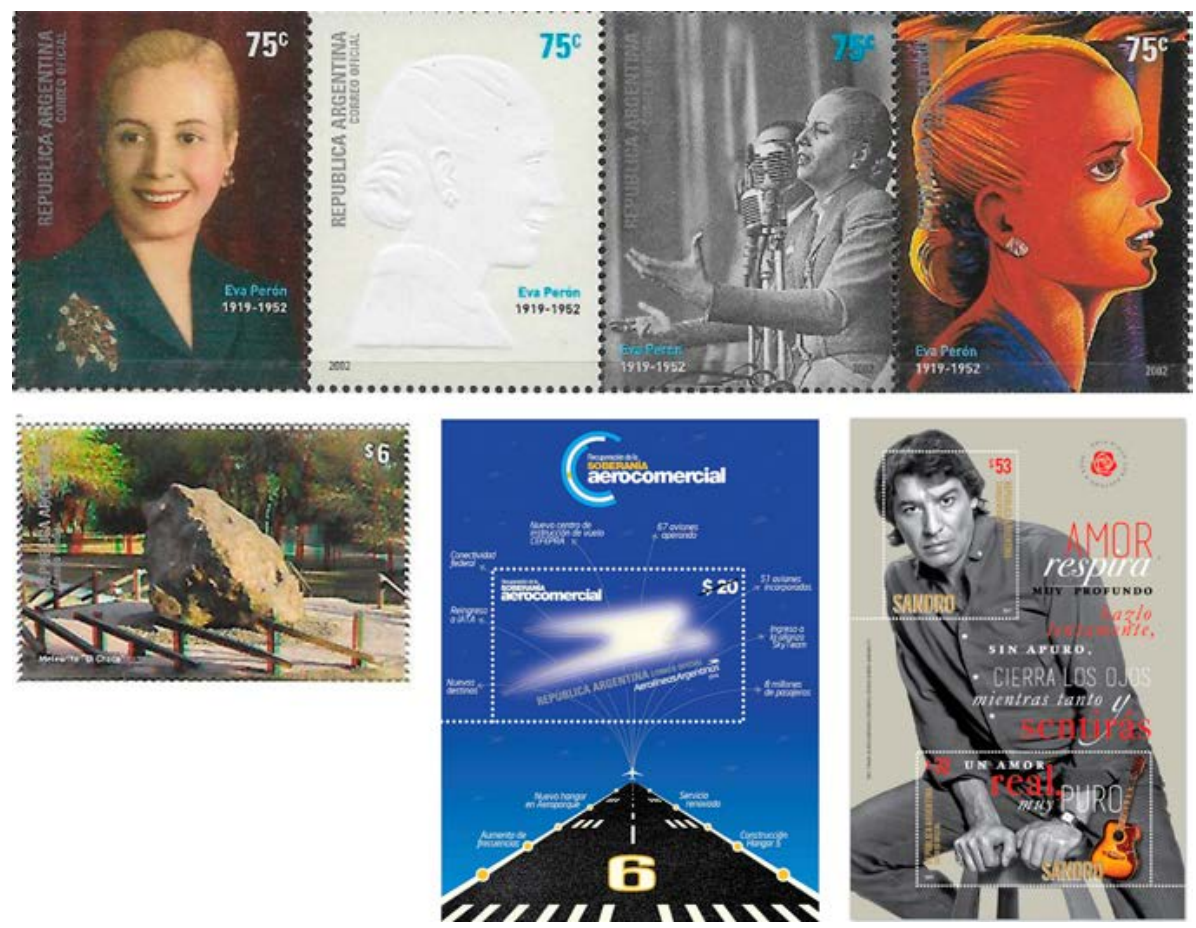

Figura 2. De izquierda a derecha: 50. Aniversario del fallecimiento de Evo Perón (2002); Meteoritos de Compo de Cielo (2007); Recuperación de la Soberanía Aerocomercial (2014) e ídolos populares: Sandro (2017)

6 Interpretada por primera vez en el álbum Sandro de América (1969), «Rosa, Rosa» es la pieza más recordada de la historia musical del Gitano. Con ella nace la mística de las rosas en sus presentaciones y a ello alude el perfume del sello postal. 


\section{CONMEMORACIONES}

Las primeras estampillas argentinas conmemorativas tuvieron por tema al 4. Centenario del Descubrimiento de América y fueron emitidas el 12 de octubre de 1892. La emisión estaba constituida por dos valores postales, uno de dos centavos y otro de cinco centavos, ambos en color azul, que presentaban la imagen de una carabela y, en sus márgenes, la leyenda «12 de octubre 1492-12 de octubre 1892» [Figura 3].
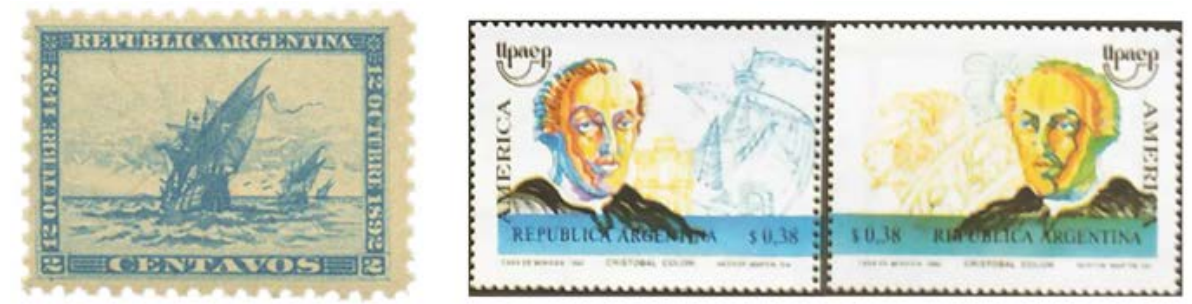

Figura 3. De izquierda a derecha: estampillas conmemorativas por el aniversario del Descubrimiento de América (1892 y 1992)

Cuando se analiza una imagen, es pertinente indagar un poco más allá de lo que se muestro e ingresar en el campo de lo que no se muestro. En este caso, se observa un paisaje marítimo, un barco que arriba transportando algo o a alguien que no se ve. Las fechas aludidas hablan de un antes y un después en la historia de los pueblos originarios latinoamericanos. El sello postal retrato una matriz de pensamiento dominante de la época. Una forma de concebir la realidad y la historia nacional. No se muestran las masacres y el exterminio de los pueblos, las violaciones a nuestras mujeres, el saqueo de nuestros recursos, el avasallamiento sobre nuestra cultura y el lenguaje. Tampoco se evoca mediante estas imágenes una reflexión o una crítica hacia la colonización y la conquista. Esto se debe a que el poder político imperante en la época de la emisión postal respondía a ideas liberales en lo económico y conservadoras en lo político y social. Respecto a este periodo, Alcira Argumedo (1993) señala:

[...] en la Argentina, luego de varias décadas de enfrentamiento de las oligarquías porteñas y del interior contra las alternativas federales, ha logrado consolidarse un régimen republicano con aspiraciones modernizantes articulado con los intereses neocoloniales de Inglaterra y fuertemente excluyente de las mayorías sociales. El nuevo poder dominante se erige a partir de la derrota y las políticas de exterminio ejercidas entre 1860 y 1880 contra las tres regiones donde se asentaban los núcleos originarios indígenas del país (p. 49).

Esta emisión postal conmemorativa, entonces, puede ser interpretada como la conmemoroción de uno de los mayores genocidios en Latinoamérica y encuentra correlato con la ideología dominante de aquel momento. Los gobiernos que implementaron políticas de ocupación del territorio, a costa de la expulsión y exterminio de los habitantes originarios, fueron los que por años sostuvieron la dicotomía entre civilización y barbarie. Por lo tanto, reivindicaron la postura colonialista civilizatoria mediante este tipo de emisiones postales. En la misma época, a nivel latinoamericano, José Martí planteaba la idea de bregar por un continente basado en la igualdad y en la soberanía, en la hermandad entre los pueblos y en el trabajo conjunto como sintetizador de las diferencias culturales. Una verdadera matriz autónoma de pensamiento latinoamericano de carácter nacional y popular.

Sin embargo, otro modo de pensamiento comenzaba a conformarse en la Argentina hacia 1891. Leandro N. Alem fundaba la Unión Cívica Radical. Alejada de la influencia mitrista, la por entonces nuevo organización política se presentaba como un movimiento nacional histórico que bregaba por afirmar valores de la vida argentina para realizar la Noción sobre bases morales, espirituales y políticas donde la prosperidad y el progreso del país residían en las virtudes de su pueblo. Esta nueva mirada se contraponía a la ideología positivista, civilizatoria y moderna del Régimen Oligárquico y reivindicaba la soberanía del pueblo como artífice de su 
propio destino exponiendo la idea de que en la República existen dos programas perpetuos, el del poseedor y el del desposeído (Argumedo, 1993). Sin embargo, lejos de aquel motor revolucionario y progresista radical de Alem, el presidente Hipólito Yrigoyen instauraba por decreto en el año 1917, al 12 de octubre como Día de la Rozo (Decreto 7112 el 4 de octubre de 1917) y dicha fecha era declarada como una fiesta nacional por la conmemoración del descubrimiento de América. Asimismo, por el Decreto 7786 del 8 de octubre de 1964, Arturo Illia estableció años más tarde su celebración en todo el territorio de la República Argentina. En 1992 se emitieron sellos postales por el 5. Centenario del Descubrimiento de América con el rostro de Cristóbal Colón. Con un valor de treinta y ocho centavos cada uno, en ellos se mostraban referencias a Europa y a la cultura americana. Habían pasado cien años de los anteriores sellos conmemorativos y la historia sobre la colonización se seguía representando de la misma manera, como un encuentro entre culturas.

Es recién en el año 2007 que, mediante el Proyecto de Ley 639/07, impulsado por la senadora Liliana Fellner, se cambia la denominación de la conmemoración por la de Día nacional del respeto a la diversidad cultural, con el objetivo de resignificar al 12 de Octubre como un día de reflexión histórica y de diálogo intercultural. En el Proyecto de Ley, Fellner (2007) señala:

Además de resultar moralmente reprochable festejar lo que para numerosos integrantes de la sociedad argentina es un genocidio, desde el punto de vista jurídico no es posible seguir considerando como una fiesta nacional el proceso de conquista y colonización de América (s. p.).

Otro caso conmemorativo para analizar son los doce sellos postales emitidos por el aniversario del Bicentenario de la Revolución de Mayo [Figura 4]. Cada estampilla resultó un reencuadre sobre el Mural Bicentenario (1810-2010), del artista Miguel Rep, presentado en formato de hoja block. El mural, encomendado por el exsecretario de Cultura de la Nación, José Nun, fue realizado en el stond de la secretaría dentro de la Feria del Libro de Buenos Aires en 2008, cuyo tema era el próximo Bicentenario. Realizado con lápiz, marcador y acrílicos sobre MDF pintado y con un tamaño de 11,66 m x 2,40 m, exhibe un recorrido sobre el período 1810-2010 con los acontecimientos más relevantes en la construcción histórica propuesta por el artista.

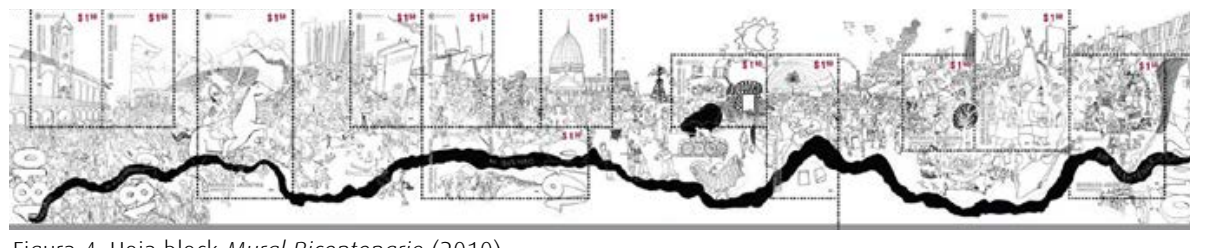

Figura 4. Hoja block Mural Bicentenario (2010)

En una entrevista, Rep señala que su punto de partida para realizar el mural fue alejarse de la historia oficial, de los próceres - exceptuando la presencia insoslayable de San Martíny de aquello que nos cuenton en la Escuela (Mural Bicentenario, s.f.). Su obra progresa, temporalmente, a fuerza de los movimientos sociales, del protagonismo del pueblo, de la gente anónima. Es por ello que se observa un gran río, que en su parte inicial se denomina Río de la Independencia y abarca hechos como la Revolución de Mayo, la Declaración de la Independencia, las guerras por la liberación, las guerras civiles, la creación de la Constitución y las oleadas inmigratorias. Otro tramo adopta la denominación de Río Centenorio y muestra los movimientos sociales de todo el siglo XX, el 17 de octubre de 1945, el bombardeo a Plaza de Mayo de 1955, la dictadura de 1976, la lucha de las Madres y Abuelas de Plaza de Mayo y el retorno a la democracia. En un último segmento, el ahora Río Bicentenario representa la crisis de 2001 y el perfil de una mujer mirando al futuro que, según el artista, expresa un deseo de que la historia deje de lado la lógica masculina de despojo y destrucción, para nutrirse del poder femenino de construir.

El mural se denomina Bicentenario porque estará en constante construcción por el historietista, donde plasmará los sucesos que ocurran en nuestro país en los tiempos venideros. Se realizó 
una versión interactiva disponible en la plataforma educativa Educ. Ar que contiene información adicional, en imágenes y videos, sobre la historia argentina. La importancia de tomar esta obra para realizar una emisión postal es destacable, porque reivindica un lenguaje plástico contemporáneo y plantea, a su vez, un juego de escala al reducirlo a una hoja block de 500 x $100 \mathrm{~mm}$, respecto del original.

Asimismo, desde una mirada historiográfica, cabe destacar que se inserta en un contexto donde el relato Bicentenorio fue el que unificó simbólicamente a la sociedad por aquellos años. También es interesante la decisión del artista de no retratar una historia protagonizada por próceres, pero sí recuperar el valor simbólico de San Martín, un personaje que se ha consolidado a través de la historia.

Al respecto, el historiador Norberto Galasso (en Ramos, 2014), sostiene que Bartolomé Mitre consideraba al Libertador como El Podre de la Patrio y logró instalar esa concepción en la sociedad. También señala que Juan Domingo Perón hace una exaltación muy importante de San Martín que se reafirma en 1950, declarado durante su mandato como el año del Libertodor, cuando se imprimen estampillas y se realizan varios actos oficiales para reivindicar su labor de emancipación. Esto se debe al valor simbólico de San Martín como un referente de adhesión y de identificación de los argentinos, idea que se recupera al inicio del tercer período peronista, cuando se sobreimprime una estampilla existente del General San Martín con la leyenda Transmisión del Mando Presidencial.

En ese sentido, cabe destacar que fue Perón quien inició la tradición, en el año 1946, de emitir sellos postales alusivos a la transmisión del mando de los distintos Presidentes de la Nación. Sin embargo, las dictaduras también han utilizado los recursos postales para conmemorar sucesos o para reivindicar personajes. Por ejemplo, se emitieron sellos conmemorativos de la por entonces denominada Revolución del 6 de septiembre de 1930 que, en realidad, fue un golpe de Estado encabezado por el general José Félix Uriburu para derrocar al gobierno de Hipólito Yrigoyen. 0 en el año 1980, en plena dictadura encabezada por Jorge Rafael Videla, se emitió un sello postal en homenaje a Pedro Eugenio Aramburu, quien ejerció la primera magistratura como dictador en el año 1955 luego de la autodenominada Revolución Libertadora que derrocó al general Perón.

\section{A MODO DE CIERRE}

Las imágenes de las estampillas no escapan a los estilos y a las características propias que brindan las nuevas técnicas y tecnologías de impresión. Es decir, la imagen visual no es estable, sino que, como señala Mirzoeff (2003), «cambia su relación con la realidad externa en los determinados momentos de la modernidad. A medida que una determinada forma de representar la realidad va perdiendo terreno, otra va ocupando su lugar sin que esta desaparezca» (p. 26). Por eso, esta forma inalterable presente durante ciertos períodos de la historia, se modifica de acuerdo a las influencias de las vanguardias, movimientos artísticos y estilos que son apropiados por nuestro país.

Por ejemplo, en el sello postal del Primer aniversario de la transferencia de los ferrocarriles o la nación (1949) se pueden reconocer tratamientos morfológicos propios del Futurismo, en el empleo dinámico de las formas y en el modelado de los volúmenes, que a partir de gradientes de color, generan brillos que remiten a lo mecánico, a lo industrial, temáticas propias de esta vanguardia y que para la fecha de emisión de la estampilla estaban en agenda en la Argentina. En el caso de los Terceros juegos deportivos panamericanos (1959), la ilustración remite al Art Decó norteamericano visible en lo geométrico de la antorcha y en el empleo de planos plenos vinculados con texturas lineales. Por su parte, en la imagen del 50. Aniversario de la Fuerzo Aéreo Argentino (1962), se podría hablar de un estilo racionalista, que apela a la síntesis de

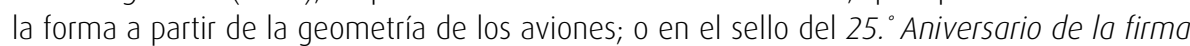
de la carto de la OEA (1975), de la influencia de la psicodelio norteamericana, muy presente 
también en el cartel cubano, evidente por la tipografía y el uso de colores sobresaturados. Asimismo, el auge de la fotografía experimental en la década del ochenta está presente en el ejemplo de la estampilla de Nociones Unidas. Año internacional de la juventud (1985); el colloge digital, como una técnica que surge con el auge de las computadoras, se puede observar en el sello conmemorativo del Centenario de la Universidad Nacional de La Plato (1997); o la composición que a partir del encuadre de la fotografía selecciona y carga de sentido a la imagen, estableciendo un juego entre los personajes retratados, se observa en la estampilla Arte contemporáneo argentino (2007). Por último, en el ejemplar de la serie Década ganada (2011), el lenguaje vectorial y sintético remite al utilizado en aplicaciones y en dispositivos móviles, característicos del siglo XXI [Figura 5].
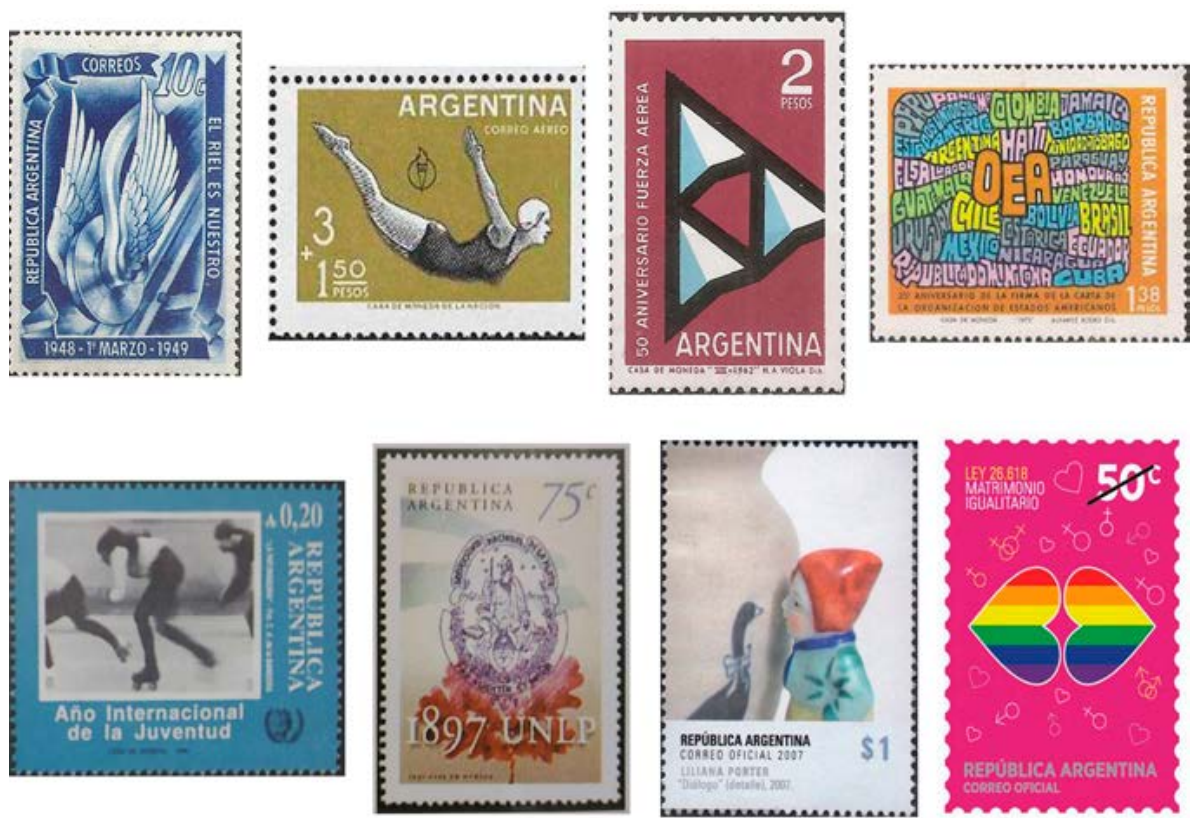

Figura 5. Ejemplos de sellos postales que evidencian la influencia de vanguardias, de movimientos artísticos y de estilos apropiados por nuestro país

Si la historia argentina fuera un álbum de figuritas, cada estampilla sería una de ellas. Esta suerte de colección se transforma, entonces, no en una historia lineal, sino en una trama que cose y descose la historia, presenta y representa distintas formas de concebir a la Argentina, diferentes miradas sobre los mismos temas que aún siguen vigentes: la independencia, la libertad, la identidad, la patria.

\section{REFERENCIAS}

Argumedo, A. (1993). Los silencios y las voces de Américo Lotina. Notos sobre el pensamiento nacional y popular. Ciudad Autónoma de Buenos Aires, Argentina: Colihue.

Belinche, D. y Ciafardo, M. (2015). El espacio y el arte. Metol, 1(1), 32-53. Recuperado de http://papelcosido.fba.unlp.edu.ar/ojs/index.php/metal/article/view/151

De Rueda, M. A. (2009). Arte, medios e historia del arte. Arte y comunicación masiva. Culturo Visual (Apunte de cátedra). Historia de los Medios y Sistemas de Comunicación Contemporáneos, Facultad de Bellas Artes, Universidad Nacional de La Plata, La Plata, Argentina.

Fellner, L. (2007). Proyecto de Ley S-639/07. Recuperado de http://www.senado.gov.ar/parlamentario/comisiones/verExp/639.07/S/PL 
Giglietti, N. y Lemus, F. (2012). Los géneros pictóricos y sus problemóticas (Apunte de cátedra). Lenguaje Visual 2B, Facultad de Bellas Artes, Universidad Nacional de La Plata, La Plata, Argentina. Recuperado de https://docs.wixstatic.com/ugd/1415a9_ef0f074c03914bed9b41fc813c7652d3.pdf

Malosetti Costa, L. y Gené, M. (Comps.). (2009). Impresiones porteños. Imagen y palabra en la historia cultural de Buenos Aires. Ciudad Autónoma de Buenos Aires, Argentina: Edhasa.

Mello Teggia, D. H. (2009). Sellos postales argentinos 1856-2010. Ciudad Autónoma de Buenos Aires, Argentina: edición del autor.

Mitchell, W. J. T. (2009). Teoría de la imagen. Ensayos sobre representación verbal y visual. Madrid, España: Akal.

Mirzoeff, N. (2003). Una introducción a la cultura visual. Ciudad Autónoma de Buenos Aires, Argentina: Paidós.

Mural Bicentenario. (s. f.). Entrevisto a Miguel Rep. «El mural nunco estará terminado». Recuperado de http:/ /muralbicentenario.encuentro.gov.ar/entrevista1.html

Pigna, F. (s. f.). El modelo agroexportador, el «granero del mundo». El historiador. Recuperado de https://www.elhistoriador.com.ar/el-modelo-agroexportador-el-granero-del-mundo/

Ramos, D. (7 de abril de 2014). El gaucho: de bandido a figura tradicional. Revisto Mito. Recuperado de http:/ /revistamito.com/el-gaucho-de-bandido-figura-tradicional/

Ravera, R. (1979). Cuestiones de estética. Ciudad Autónoma de Buenos Aires, Argentina: Correo de Arte.

Zátonyi, M. (2007). Arte y creación. Los caminos de la estética. Ciudad Autónoma de Buenos Aires, Argentina: Claves para todos. 